\title{
INTERNAL FRICTION AND MECHANICAL SPECTROSCOPY OF METALS AND ALLOYS
}

This issue of the journal is devoted to the anniversary of professor, doctor of engineering sciences Stanislav Alekseevich Golovin (Tula State University), who is one of the forefathers of the scientific specialization "Internal friction and mechanical spectroscopy of metals and alloys" in our country. Internal friction is without exception an integral property of all solid materials, and based on this property the method of mechanical spectroscopy makes it possible to resolve a broad range of problems of physical materials sciences. Articles are presented below on this theme by scientists from Moscow, Voronezh, Tula, Vyatka, Ufa, Khar'kov, and Vinnitsa. Some articles will be published in No. 6 .

Reviewer and scientific editor of the current thematic issue - professor, doctor of physical mathematical sciences I. S. Golovin. 